Research Article

\title{
A comparative study of dexmedetomidine vs midazolam for sedation and hemodynamic changes during tympanoplasty and modified radical mastoidectomy
}

\author{
Dhara A. Vyas $^{1}$, Nikunj H. Hihoriya ${ }^{2} *$, Rina A. Gadhavi ${ }^{1}$
}

${ }^{1}$ Department of Anaesthesia, C. U. Shah Medical College, Surendranagar-363001, India ${ }^{2}$ Department of Pharmacology, GCS Medical College, Hospital and Research Centre, Ahmedabad-380025, India

Received: 10 August 2013 Accepted: 29 August 2013

*Correspondence to:

Dr. Nikunj H. Hihoriya,

Email:

hihoriyanikunj@gmail.com

(C) 2013 Vyas DA et al. This is an open-access article distributed under the terms of the Creative Commons Attribution Non-Commercial License, which permits unrestricted non-commercial use, distribution, and reproduction in any medium, provided the original work is properly cited.

\begin{abstract}
Background: The benzodiazepine, Midazolam, has been used medication given for sedation in tympanoplasty and mastoidectomy because of a number of beneficial effects. However, Dexmedetomidine is a highly selective $\alpha 2$ adrenoceptor agonist is emerging as preferred choice now a day. The aim of the study is to compare hemodynamic stability and sedation under Dexmedetomidine vs Midazolam during tympanoplasty and modified radical mastoidectomy done under local anaesthesia.

Methods: After obtaining ethics clearance from institution and written informed consent from patients, 50 patients of age group 15 to 50 years of ASA grade i \& ii were selected and divided in to two groups:

Group D: Inj. Dexmedetomidine $1 \mu \mathrm{g} / \mathrm{kg}$ over $15 \mathrm{~min}$, followed by $0.5 \mu \mathrm{g} / \mathrm{kg} / \mathrm{hr}(\mathrm{n}=25)$.

Group M: Inj. Midazolam $0.05 \mathrm{mg} / \mathrm{kg}$ i.v. slowly, followed by $0.01 \mathrm{mg} / \mathrm{kg} / \mathrm{hr}(\mathrm{n}=25)$.

Arterial blood pressure, heart rate and sedation level were monitored. The surgeons and patients were asked to rate their satisfaction, using the Likert scale.

Results: Sedation score difference between group Dand group $M$ was not statistically significant. There was no statistically significant difference found in diastolic blood pressure of both the groups. There was a significant reduction in heart rate in group D as compared to group M. Surgeon's satisfaction score and patient's satisfaction score both were high in group D compare to group $\mathrm{M}$.

Conclusions: For monitored anaesthesia care in ENT surgeries performed under local anaesthesia, inj. Dexmedetomidine could be a better alternative over inj. Midazolam.
\end{abstract}

Keywords: Dexmedetomidine, Midazolam, ENT surgeries

\section{INTRODUCTION}

Tympanoplasty and mastoidectomy are descriptive terms defining surgical procedures that address pathology of the tympanic membrane and middle ear. Tympanoplasty implies reconstruction of the tympanic membrane but also deals with pathology within the middle ear cleft, such as chronic infection, cholesteatoma, or an ossicular chain problem. Tympanoplasty is usually performed under general anesthesia although patients who are reluctant to undergo general anesthesia may be given local anesthesia supplemented with intravenous sedation. ${ }^{1}$ There are many advantages of local anesthesia supplemented with intravenous sedation, such as less bleeding, cost-effectiveness, postoperative analgesia, faster mobilization of the patient, and the ability to test hearing intraoperatively. ${ }^{2}$ Monitored anaesthesia care (MAC) typically involves administration of local anaesthesia in combination with IV sedatives, anxiolytic and/or analgesic drugs which is a common practice during various ENT surgical procedures. ${ }^{3}$

Midazolam is a potent imidazobenzodiazepine which possesses typical benzodiazepine properties namely hypnotic, amnestic, anticonvulsant and anxiolytic activity. The benzodiazepine, Midazolam, has become the most frequently used medication given for sedation. Midazolam has a number of beneficial effects when used for sedation, fast onset, and limited duration of action. Despite having a number of beneficial effects, it is far from an ideal agent having untoward side effects such as restlessness, paradoxical reaction, cognitive 
impairment, amnesia, and respiratory depression. ${ }^{4,5} \mathrm{New}$ drugs, such as the $\alpha_{2}$-agonists, have emerged as alternatives for iv sedation. Dexmedetomidine is a highly selective $\alpha_{2}$-adrenoceptor agonist that has sedative and analgesic effects. ${ }^{6}$ Clinical investigations have demonstrated its sedative, analgesic and anxiolytic effects after IV administration to volunteers and postsurgical patients. ${ }^{7,8}$ Dexmedetomidine is a novel analgesic agent that helps at preoperative state, postoperative period and during surgery especially for hemodynamic stability. ${ }^{9}$

\section{METHODS}

After ethical committee approval 50 patients of physical status ASA grade 1-2 aged between 15-50 years undergoing ear surgery were randomly selected from C.U. Shah Medical Collage, ENT OT. A Preoperative visit was made on the day prior to plan surgery. All routine investigations were done. Patients were explained about the concerned technique $\&$ informed consent taken. Patients were instructed to keep fasting for 6-8 hours. All the resuscitation and monitoring equipments in the form of bag-valve-mask system, laryngoscope, endotracheal tubes and emergency drugs were left prepared in the operating room, for management of any adverse reactions.

On the morning of surgery, Baseline $\mathrm{HR}, \mathrm{SpO}_{2}$ and $\mathrm{BP}$ were recorded. The 20-gauge venous cannula was inserted into the dorsum of the hand. Premedication in the form of inj. Glycopyrrolate [10 $\mathrm{mcg} / \mathrm{kg}$ of body weight] and inj. Diclofenac 75 intramuscularly $30 \mathrm{~min}$ before operative procedure were given.

Patients were randomly allocated in 2 groups as follows:

Group D: Dexmedetomidine group $(n=25)$ - Inj. Dexmedetomidine $1 \mu \mathrm{g} / \mathrm{kg}$, over $10 \mathrm{~min}$ followed by $0.5 \mu \mathrm{g} / \mathrm{kg} / \mathrm{hr}$.

Group M: Midazolam group $(\mathrm{n}=25)$ - Inj. Midazolam $0.05 \mathrm{mg} / \mathrm{kg}$ diluted i.v. slowly, followed by $0.01 \mathrm{mg} / \mathrm{kg} / \mathrm{hr}$.

Both groups also received inj. Ondansetron $0.15 \mathrm{mg} / \mathrm{kg}$ i.v. and inj. DNS 1 litre started slowly.

Sedation level was measured by Ramsay sedation scale. As Ramsay score of 3 was achieved and hemodynamic and respiratory stability was ensured, procedure can be started. Local anaesthesia was given by the operating surgeon, using xylocaine $2 \%$ with adrenaline 1:200,000. Systolic blood pressure, diastolic blood pressure, heart rate and peripheral oxygen saturation were monitored continuously at 15-min interval during the study by anesthesiologist. Patients were allowed to breathe spontaneously without an artificial airway during the procedure. Intraoperative bleeding was assessed by bleeding scale (0-4).
Patients were asked to answer the question, 'How would you rate your experience with the sedation (or analgesia) you have received during surgery?' using a 7-point Likert verbal rating scale. This assessment of patient's satisfaction with sedation and analgesia was performed just before shifting to ward to minimize the effects of sedation on patient's judgment. Moreover, the surgeons were asked to rate their satisfaction with operative conditions, using the same scale at the end of surgery.

If the level of $\mathrm{SpO} 2$ decreased below $93 \%$ for 30 seconds then neck was extended slightly and oxygen was administered via nasal mask, and the study drug infusion was discontinued temporarily. If heart rate decreased below $60 / \mathrm{min}$ then inj. atropine $0.01 \mathrm{mg} / \mathrm{kg}$ was given. If mean blood pressure decreased below $65 \mathrm{~mm} / \mathrm{hg}$ then inj. $\mathrm{RL}$ and vasopressor were given as required. Arterial BP, $\mathrm{HR}$, and $\mathrm{SaO} 2$ were measured every 15 min during the operative period. Occurrence of nausea, vomiting, hypotension, hypertension, bradycardia or desaturation was recorded till 2 hours postoperatively.

Various scores used in the study are as follows:

\section{A. Sedation scale (Ramsay Sedation Scale)}

[1 - Anxious, agitated or restless, 2 - Cooperative, oriented and tranquil, 3 - Responds to command, 4 Asleep but has a brisk response to light glabellar tap or loud auditory stimulus, 5 - Asleep has a sluggish response to a light glabellar tap or loud auditory stimulus, 6 Asleep no response]

\section{B. Intraoperative bleeding scale}

[0 - No bleeding, 1 - Slight bleeding; no suctioning of blood required, 2 - Slight bleeding; occasional suctioning required. Surgical field not threatened, 3 - Slight bleeding; frequent suctioning required. Bleeding threatened surgical field a few seconds after suction was removed, 4 - Moderate bleeding; frequent suctioning required. Bleeding threatened surgical field directly after suction was removed]

\section{Likert Scale}

[1- Extremely dissatisfied, 2- Dissatisfied Somewhat, 3Dissatisfied, 4- Undecided Somewhat, 5- Satisfied, 6Satisfied extremely satisfied]

\section{RESULTS}

A study of 50 patients aged between 15-50 yrs undergoing tympanoplasty and mastoidectomy were randomized into 2 groups with 25 patients in Group D (Dexmedetomidine) and 25 patients in Group $\mathrm{M}$ (Midazolam). The study was undertaken to compare the sedative, analgesic and hemodynamic changes of Dexmedetomidine vs Midazolam. Demographic data is shown in Table 1. 
Table 1: Demographic data of patients of group D and group $\mathbf{M}$

\begin{tabular}{|lll|}
\hline Parameter & $\begin{array}{l}\text { Group D } \\
(\mathbf{n}=\mathbf{2 5})\end{array}$ & $\begin{array}{l}\text { Group M } \\
(\mathbf{n}=\mathbf{2 5})\end{array}$ \\
\hline $\begin{array}{l}\text { Age in yrs } \\
(\text { Mean } \pm \text { SD) }\end{array}$ & $29 \pm 8.4$ & $26.76 \pm 8.76^{*}$ \\
\hline Sex & $\begin{array}{l}12-\text { male } \\
13-\text { female }\end{array}$ & $\begin{array}{l}14-\text { male* }^{*} \\
11-\text { female* }\end{array}$ \\
\hline $\begin{array}{l}\text { ASA grade } \\
\text { (Mean } \pm \text { SD) }\end{array}$ & $1.4 \pm 0.5$ & $1.24 \pm 0.44^{*}$ \\
\hline $\begin{array}{l}\text { Duration of } \\
\text { surgery in minutes } \\
\text { (Mean } \pm \text { SD) }\end{array}$ & $141 \pm 38.49$ & $\begin{array}{l}146.4 \pm \\
40.45^{*}\end{array}$ \\
\hline
\end{tabular}

*The $p$ value observed was $>0.05$ as compare to group D \& was found to be statistically not significant.

Sedation score difference between group Dand group $\mathrm{M}$ was not statistically significant (Table 2 and Figure 1). Bleeding score was less in group D compare to group $\mathrm{M}$ $(p<0.01)$. Surgeon's satisfaction score and patient's satisfaction score both were high in group D compare to group M $(p<0.01)$.

Table 2: Various score of patients of group D and group $\mathbf{M}$

\begin{tabular}{|lll|}
\hline Parameter & Group D & Group M \\
\hline Sedation Score & $3.64 \pm 0.86$ & $3.32 \pm 0.63^{*}$ \\
\hline Bleeding Score & $1.67 \pm 0.96$ & $1.92 \pm 0.64^{\#}$ \\
\hline $\begin{array}{l}\text { Surgeon's } \\
\text { Satisfaction Score }\end{array}$ & $5.52 \pm 0.71$ & $4.12 \pm 0.92^{\#}$ \\
\hline $\begin{array}{l}\text { Patient's } \\
\text { Satisfaction Score }\end{array}$ & $5.36 \pm 0.64$ & $4.28 \pm 0.67^{\#}$ \\
\hline
\end{tabular}

$* p$ value $>0.05$ as compare to group D (Not significant) ${ }^{\#} p$ value $<0.05$ as compare to group D (Significant)

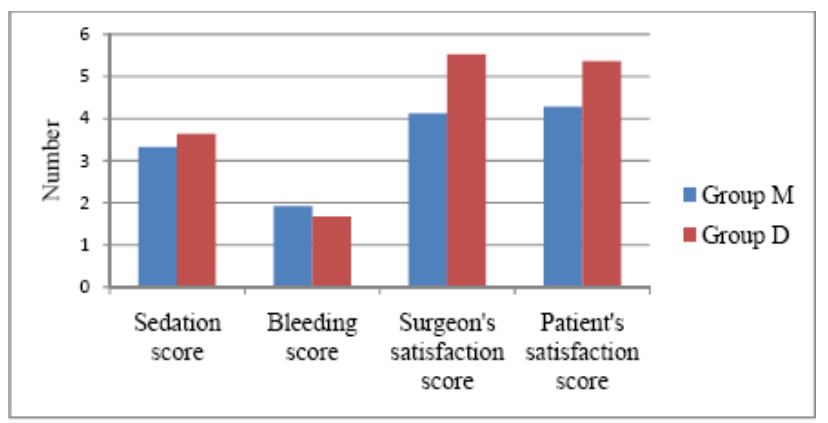

Figure 1: Various scores of patients of group D and group $\mathrm{M}$.

Systolic Blood pressure decreased significantly after administration of the drug in group $\mathrm{D}$ than in group $\mathrm{M}$ as shown in figure 2 . There was no statically significant difference found in diastolic blood pressure of both the groups as shown in figure 3. Mild hypotension was noted in Dexmedetomidine group which was responsive to I.V. fluids. There was a significant reduction in heart rate in group D as compared to group M (Figure 4).

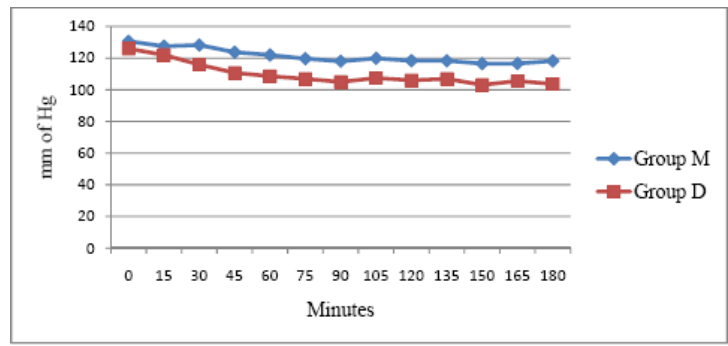

Figure 2: Changes in systolic blood pressure of patients.

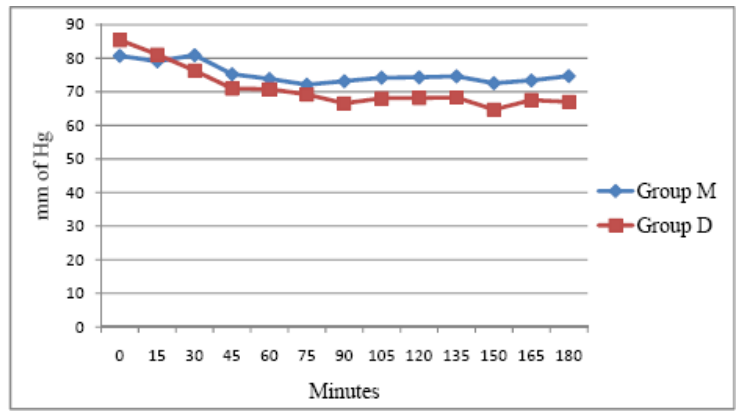

Figure 3: Changes in patient's diastolic blood pressure of patients.

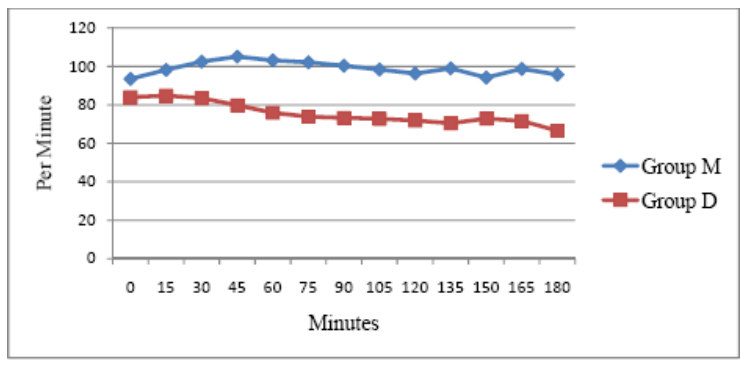

Figure 4: Changes in heart rate of patients.

\section{DISCUSSION}

Monitored Anaesthesia Care (MAC) is a technique of combining local anaesthesia with parenteral drugs for sedation and analgesia. ${ }^{10}$ A common practice with sedation is that the sedative drug is given in larger doses in an attempt to achieve a calm, pain free patient. ${ }^{11}$ Monitored anesthesia care (MAC) is useful for various clinical fields such as minimally invasive surgery, gastrointestinal endoscopy, and interventional or radiological procedures. It provides suitable intraoperative conditions as well as comfort for patients. The commonly used drugs are Midazolam, Propofol, and opioids such as Fentanyl, Alfentanil or Remifentanil. Occasionally, the administration of sedatives or hypnotics in conjunction with analgesics can cause significant respiratory depression and/or transient upper airway 
obstruction. ${ }^{12}$ Since the approval of Midazolam by FDA in $1985,{ }^{13}$ practitioners of all medical disciplines embraced the versatility provided by Midazolam though the risk of losing airway control, hypoxia and hypotension with higher doses of Midazolam has also been recognized.

Monitored anaesthesia care (MAC) may be applied for various ENT surgeries in which an adequate sedation and analgesia without respiratory depression are desirable for comfort of both the patient and the surgeon. ${ }^{14}$ In order to reduce the incidence of complications, it is important to have a bloodless surgical field as far as possible for better visibility. Bleeding control is usually attained with local application of epinephrine. ${ }^{15}$ Pain during surgery may lead to sympathetic stimulation and a restless patient may have tachycardia and hypertension, leading to increased bleeding in the surgical field. Several drugs have been used for sedation during surgery under local anaesthesia with monitored anaesthesia care including Propofol, benzodiazepines and opioids. However, Propofol may cause over sedation and disorientation, benzodiazepines may result in confusion, particularly in elderly and opioids are associated with increased risk of respiratory depression and oxygen desaturation. All of these untoward effects may hamper patient's cooperation during surgery and would make these agents less than ideal for the intraoperative management of sedation in MAC. Midazolam is the most frequently used sedative and has been reported to be well tolerated when used in MAC.

Dexmedetomidine is a highly selective $\alpha_{2}$-adrenoceptor agonist with eight times higher specificity for the receptor compared to clonidine. It provides excellent sedation and analgesia with minimal respiratory depression. Recent multicenter trial indicated that it was an effective baseline sedative for patients undergoing a broad range of surgical procedures under MAC, providing greater patient satisfaction, less opioid requirements, and less respiratory depression compared with the placebo. ${ }^{16}$ In patients undergoing diagnostic transesophageal echocardiography, the sedative effect of Dexmedetomidine proved to be equivalent to that of the standard therapy using Midazolam and Fentanyl without increasing the incidences of respiratory depression or oxygen desaturation. It also seemed to be better in terms of hemodynamic results.

In the current issue of the Korean Journal of Anesthesiology, ${ }^{17}$ the author demonstrated Dexmedetomidine was a useful sedative drug for MAC in outpatients undergoing cataract surgery, and in aspects of patients' satisfaction and cardiovascular stability. We chose a loading dose $1 \mathrm{mcg} / \mathrm{kg}$ of Dexmedetomidine based on previous literature and studies. Reports suggest that on administration of Dexmedetomidine, $\alpha_{2}$ agonist effects are observed but not $\alpha_{1}$ effect. In view of its short distribution half life of 5 min Dexmedetomidine necessitates that it be given as a maintenance infusion. $\alpha_{2}$-agonists produce a modest reduction in blood pressure (BP) and heart rate
(HR). In our study when Dexmedetomidine was infused in patients it produced reduction in BP \& pulse, 8.14\% $18.14 \%$ reduction in systolic blood pressure, $5 \%-24 \%$ reduction seen in diastolic blood pressure and in HR $20 \%$ reduction was seen. Midazolam did not produced significant changes in BP \& pulse, $1.83 \%-9.61 \%$ reduction in systolic blood pressure, $10.6 \%$ decrease and $0.24 \%$ increase in diastolic blood pressure and $0.7 \%-12.3 \%$ increase in HR is seen Oxygen saturation was maintained in both the groups. Devangi A. Parikh et al., evaluate Dexmedetomidine vs Midazolam-Fentanyl in tympanoplasty, they said that lower HR and MAP in Dexmedetomidine group in comparison to the Midazolam -Fentanyl group could be explained by the markedly decreased sympathetic activity. There finding were similar to other studies where lower HR and MAP were observed in the Dexmedetomidine group. There result suggest that Dexmedetomidine has clinical advantage over Midazolam in providing a better operative field for microscopic surgery. ${ }^{18}$ Durmus et al, have evaluated this property of Dexmedetomidine for providing controlled hypotension in general anaesthesia for tympanoplasty cases and concluded that it is a useful adjuvant to decrease bleeding when a bloodless surgical field is required. Kumari I.et al, done Comparison of clonidine versus Midazolam in monitored anesthesia care during ENT surgery. They evaluate intragroup variations, mean $\mathrm{HR}$ and MAP showed a significant fall from baseline in Clonidine Group, whereas they showed a significant rise from baseline in Midazolam Group. On intergroup comparison mean HR and MAP were significantly less in Group $\mathrm{C}$ as compared to Group $\mathrm{M}^{3}$

Midazolam causes sedation by GABA receptor activation. $\alpha_{2}$ receptors are found densely in the pontine locus ceruleus which is an important source of sympathetic nervous system innervations of the forebrain and a vital modulator of vigilance. The sedation effects evoked by $\alpha_{2}$ agonists most likely reflects inhibition of this nucleus. In our study, sedation score was slightly higher in group D compare to group $\mathrm{M}$, but $\mathrm{P}>0.05$ indicate that statistically no significant difference found between group $D$ and group $M$. Devangi A. Parikh et al., evaluate Dexmedetomidine vs Midazolam Fentanyl in tympanoplasty, in there study both the drugs were comparable in terms of sedation as none of the patient in ether group required additional sedation with Propofol or any alternative anaesthesia technique, as in our study. ${ }^{18}$

In our study, bleeding score was less in group D compares to group $\mathrm{M}$, indicate that Dexmedetomidine reduces blood loss and provide better surgical condition in comparison to Midazolam. Kumari I.et al, compared the use of intravenous Clonidine and Midazolam premedication in MAC for ENT surgeries conducted under local anaesthesia. They found that intraoperative bleeding was significantly less in Clonidine group as compared to Midazolam group, as reported earlier. Controlled hypotension effectively reduces surgical blood 
loss and improves surgical conditions. Clonidine and Dexmedetomidine both are found effective in reducing bleeding in ENT surgeries. ${ }^{3}$

In our study Surgeon's satisfaction score and patient's satisfaction score both were high in group D compare to group M. Parikh DA et al., evaluate Dexmedetomidine vs Midazolam-Fentanyl in tympanoplasty, they demonstrated significantly higher patient and surgeon satisfaction scores with Dexmedetomidine. The lower HR and MAP in these patients could have probably resulted in a better surgical field thus attributing to better surgeon satisfaction. K. Karaaslam et al, demonstrated Dexmedetomidine used significantly less rescue Tramadol in comparison to group Midazolam when both the drugs were compared in FESS and nasal septoplasties. Analgesic property of $\alpha_{2}$ agonists like Dexmedetomidine with its opiate-sparing properties conducted in general anaesthesia with dexmeditomidine. ${ }^{18}$

So by summarizing above comparisons we can conclude that for monitored anaesthesia care in ENT surgeries performed under local anaesthesia, intravenous Dexmedetomidine could be a better alternative compared to conventional sedation with Midazolam, since it provides a calm patient with better intraoperative analgesia, and a bloodless surgical field leading to increased satisfaction of both patient and surgeon.

\section{Funding: None}

Conflict of Interest: None declared

Ethical approval: The study was approved by the institutional ethics committee

\section{REFERENCES}

1. Norman Friedman, M.D. et al Tympanoplasty, Grand Rounds Presentation, UTMB, Dept. of Otolaryngology, June 9, 1999.

2. Sarmento KM Jr, Tomita S. Retroauricular tympanoplasty and tympanomastoidectomy under local anesthesia and sedation. Acta Otolaryngol. 2009 Jul;129(7):726-8.

3. Kumari I, Naithni U, Bedi V, Gupta S, Gupta R, Bhuie. Comparison of clonidine versus Midazolam in monitored anesthesia care during ENT surgeryA prospective, double blind, randomized clinical study. Anaesth Pain \& Intensive Care 2012;16(2): 157-64.

4. Bergendahl H, Lönnqvist P, Eksborg S. Clonidine: an alternative to benzodiazepines for premedication in children. Curr Opin Anaesthesiol 2005;18:608-13.

5. Bergendahl H, Lönnqvist P, Eksborg S. Clonidine in paediatric anaesthesia: review of the literature and comparison with benzodiazepines for premedication. Acta Anaesthesiol Scand 2006;50:135-43.
6. Hall JE, Uhrich TD, Barney JA, et al. Sedative, amnestic, and analgesic properties of small-dose Dexmedetomidine infusions. Anesth Analg 2000;90:699-705.

7. Taittonen MT, Kirvela OA, Aantaa R, et al. Effect of clonidine and Dexmedetomidine premedication on perioperative oxygen consumption and haemodynamic state. Br J Anaesth 1997;78:400-6.

8. Aantaa R, Jaakola ML, Kallio A, et al. Reduction of the minimum alveolar concentration of isoflurane by Dexmedetomidine. Anesthesiology1997;86:105560.

9. Edussuriya B, Goonasekera CD, Rajapakse M, Rajapakse VP, Jayasooriya D. Middle ear surgery under local anaesthesia and sedation. Ceylon Med J 1997;42:75-7.

10. American Society of Anesthesiologists. Standards for Basic Intraoperative Monitoring 1986. Available at http://www asahq.org/Standards/02.html. Accessed 23 May 2013.

11. Council of Dental Education, American Dental Association. Guidelines for teaching the comprehensive control of pain and anxiety in dentistry. J Dent Educ 1972;36:62-7.

12. Soo Kyung LeeClinical use of Dexmedetomidine in monitored anesthesia care Korean J Anesthesiol. 2011 December; 61(6): 451-452.

13. Philip BK. Supplemental medication for ambulatory procedures under regional anaesthesia. Anesth Analg 1985;64:1117-25.

14. Danielsen A, Gravningsbraten R, Olofsson J. Anaesthesia in endoscopic sinus surgery. Eur Arch Otorhinolaryngol 2003;260:481-6.

15. Fedok FG, Ferraro RE, Kingsley CP, Fornadley JA. Operative times, postanaesthesia recovery times, and complications during sinonasal surgery using general anaesthesia and local anaesthesia with sedation. Otolaryngol Head Neck Surg 2000;122:560-6.

16. Candiotti KA, Bergese SD, Bokesch PM, Feldman MA, Wisemandle W, Bekker AY, et al. Monitored anesthesia care with Dexmedetomidine: a prospective, randomized, double-blind, multicenter trial. Anesth Analg. 2010;110:47-56.

17. Na HS, Song IA, Park HS, Hwang JW, Do SH, Kim CS. Dexmedetomidine is effective for monitored anesthesia care in outpatients undergoing cataract surgery. Korean J Anesthesiol. 2011;61:453-9.

18. Parikh DA, Kolli SN, Karnik HS, Lele SS, Tendolkar BA. A prospective randomized doubleblind study comparing dexmedetomidine vs. combination of midazolam-fentanyl for tympanoplasty surgery under monitored anesthesia care. J Anaesthesiol Clin Pharmacol. 2013 Apr;29(2):173-8.

doi:10.5455/2319-2003.ijbcp20131010

Cite this article as: Vyas DA, Hihoriya NH, Gadhavi

RA. A comparative study of dexmedetomidine vs midazolam for sedation and hemodynamic changes during tympanoplasty and modified radical

mastoidectomy. Int J Basic Clin Pharmacol 2013;2:562-6. 